\title{
Nosso passado terá um futuro? Reflexões sobre a arqueologia
}

\author{
Our past will have a future? Reflections on archeology \\ Nuestro pasado tendrá futuro? Reflexiones sobre la arqueología
}

ArnoAlvarez Kern*

\section{Resumo}

O homem é uma extraordinária singularidade no mundo dos seres vivos ao se perguntar sobre as suas origens, ao construir discursos míticos ou históricos sobre seu passado e ao escavar o solo e encontrar os arquivos, que contêm os vestígios de seus antecessores. Somos responsáveis por esses milhares de vestígios da cultura material, que nos abrem novas perspectivas através de seu estudo, em busca das respostas que cada geração formula sobre o seu passado e o da humanidade. $\mathrm{O}$ artigo evoca reflexões sobre a epistemologia e a função social da arqueologia, destacando a relevância do estudo, a compreensão e a proteção dos testemunhos documentais, para garantir, assim, a sobrevivência do futuro de nosso passado, enquanto humanidade.

Palavras-chave: Arqueologia. Ciência. Função Social. História.
Em nossa sociedade ocidental, nem todos valorizam os estudos sobre o passado da humanidade. Muitas pessoas afirmam, sem dúvida com algum exagero, não terem nenhum interesse em saber se existiram homens antes de nós e considerarem seu estudo sempre uma perda de tempo. Afirmações categóricas deixam claro, como se fossem verdades indubitáveis, que o papel da ciência deveria se restringir à solução dos problemas mais imediatos da sociedade atual, como o saneamento, a pobreza e o combate às doenças. Ainda segundo essa lógica, o patrimônio do passado, tanto natural como

\footnotetext{
Doutor em Arqueologia pela Ecole des Hautes Etudes en Sciences Sociales, França. Pesquisador do CNPq. Membro da Sociedade Brasileira de Arqueologia. Professor Titular aposentado da Universidade Federal do Rio Grande do Sul e da Pontifícia Universidade Católica do Rio Grande do Sul, Brasil. E-mail: aakern40@gmail.com
}

Recebido em 30/07/2016 - Aprovado em 18/12/2016 http://dx.doi.org/10.5335/hdtv.17n.1.7234 
cultural, poderia ser destruído sem maiores problemas, para ceder lugar aos avanços inexoráveis do futuro, seja lá o que esta palavra realmente signifique.

Entretanto, a realidade do passado não deixa de existir porque alguns ignoram a sua existência. Reconstruir uma realidade passada a partir dos raros indícios remanescentes não é apenas um problema acadêmico ou o objetivo da arqueologia e da história, mas um problema tão antigo como a humanidade. Basta imaginarmos as dificuldades do caçador pré-histórico que, à noite, já no acampamento e à luz da fogueira, tenta descrever, em detalhes, as aventuras da caçada de mamutes ocorrida durante o dia. Podemos igualmente imaginar Heródoto e Tucídides, os primeiros historiadores gregos, tentando descrever as façanhas épicas das guerras mundiais de sua época, envolvendo os helenos contra os persas ou os atenienses contra os espartanos.

Podemos nos dar conta igualmente das dificuldades dos detetives de nossa época, tentando desvendar um assassinato, também ocorrido no passado; como descobrir a identidade da vítima e imaginar o que realmente aconteceu a partir dos raros indícios encontrados na cena do crime; como descobrir o criminoso a partir das impressões digitais no cabo da faca abandonada no solo e de outras evidências encontradas: uma caixa de fósforos, um tíquete de ônibus, algumas pegadas no solo.

O número de pessoas que se interessa pelo passado da humanidade é muito grande em nossa sociedade ocidental, na Europa e na América. Ele é muito maior do que em outras sociedades atuais. Afirma-se mesmo que esse interesse seja uma das característi- cas da nossa sociedade desde Heródoto, que usou o conceito de história, e Tucídides, o de arqueologia em seus livros, nas cidades da Grécia antiga.

Em nossa sociedade ocidental, não são apenas especialistas, como os historiadores e os arqueólogos, que se voltam para o passado da humanidade. Desde a Idade Média, teólogos e sacerdotes referem-se a uma história do sagrado, na qual examinam as ações de homens considerados santos e, acima de tudo, tentam compreender os desígnios insondáveis da providência e suas interferências na vida dos homens, nos quadros de uma Teologia da História. Desde o século XVIII, intelectuais voltados para a Filosofia da História, como Voltaire, Hegel, Spengler e Toynbee, elaboraram detalhadas e complexas interpretações que julgaram adequadas para explicar o panorama global da história da humanidade.

Diariamente, jornalistas escrevem na mídia textos que se apresentam como uma crônica da atualidade, fazendo referências à multiplicidade de acontecimentos da história do tempo presente, mas, só eventualmente, fazendo referências também aos acontecimentos do tempo passado. Eles tentam organizar esses fatos diversos em suas páginas sobre política, economia, cultura, esporte e crônica social e policial. Nem sempre estão preocupados em explicar o processo global da história da humanidade ou em dar um sentido ao conjunto das informações. Mas, sem dúvida, estão entre aqueles que reconhecem a importância da compreensão de nosso passado.

Paleontólogos, palinólogos e geomorfólogos escrevem também páginas sobre 
a história natural, ou seja, sobre o passado da natureza em nosso planeta. Descrevem, em seus textos, as transformações por que passaram a fauna, a flora e o relevo. Dessa história emergem mundos inesperados: paisagens exóticas e seres estranhos, muito diferentes dos que podemos observar hoje em dia. Apresentam aos nossos olhares, admirados, relevos, floras e faunas, que parecem saídas de obras de ficção científica. Essas diversas visões do passado da natureza, incluindo aquele da humanidade fóssil (homo habilis, homo erectus, homo de neanderthal, etc.), não são as mesmas dos historiadores e dos arqueólogos.

\section{Ciências de qual tempo?}

Já se afirmou algumas vezes que a arqueologia e a história são ciências do passado, o que não é verdade, por diversas razões. Em primeiro lugar, não o é por ser uma afirmação ampla em demasia. Essas ciências não trabalham visando o passado do universo, nem o das espécies animais nem o de nosso planeta. O seu interesse somente desperta quando começa a surgir a espécie humana, organizada em sociedade e produzindo cultura. Não vemos arqueólogos e historiadores fazerem referências à história do sistema solar, ao Big bang e à expansão do universo, muito menos à era dos dinossauros ou aos fenômenos relacionados a um provável aquecimento global. Para um arqueólogo, as atividades vulcânicas em Santorini ou do Vesúvio só passam a ter interesse se relacionadas à morte dos moradores dos sítios arqueológicos de Akrotiri, de Herculano e de Pompéia.
A arqueologia tem atualmente um público cada vez mais interessado. Ele pode ser visto tanto nas exposições arqueológicas de museus, como diante das grandes telas do cinema, para acompanhar novos filmes de Indiana Jones ou Lara Croft, ou frente às pequenas telas da televisão, para seguir atentamente as séries nas quais pretensos arqueólogos de chapéu de couro descobrem a "verdade", desvendam os "mistérios" e apresentam-nos as "relíquias" escondidas do passado. O motivo que atrai esse público é a súbita exposição de um passado oculto e, até então, ignorado, que se desvela subitamente no presente, aparentemente tangível e compreensível, diante de seus olhos curiosos.

Juntamente com o historiador, o arqueólogo se situa na vanguarda dos que produzem conhecimento científico sobre o nosso passado, ou seja, sobre aquele vivido pelos homens ao longo do tempo. Ambos buscam interpretar os vestígios deixados pelas sociedades do passado, identificando os traços da passagem dos homens que nos precederam. Procuram entender as suas ações e reações face ao meio ambiente, as relações que os diversos grupos humanos tiveram uns com os outros as suas heranças culturais e as transformações por que passaram ao longo do tempo.

Estas duas ciências divergem, entretanto, pelas abordagens desses vestígios, adaptada cada uma delas às características essenciais de cada tipo de fonte. Quase sempre, os arqueólogos estão às voltas com a cultura material, enquanto os documentos escritos atraem os historiadores. Para o arqueólogo, o passado é, antes de tudo, matéria: objeto, monumento, templo, túmulo, esqueleto humano, mas também fossa culinária, pe- 
gada, pólen. Para o historiador, o passado é, inicialmente, uma informação verbal de um testemunho oral que ele pode escutar e compreender. É também uma inscrição em pedra, um manuscrito ou um impresso em uma língua cujo código lhe é compreensível. Ou seja, no conjunto de suas atividades de investigação, ambos estão interessados em todo e qualquer traço ou evidência do ser humano que possa identificar e ajudar a reconstituir um passado. Criaram-se, assim, as ciências humanas voltadas para os homens organizados em sociedades ao longo do tempo, visando preservar esse patrimônio cultural passado, compreendê-lo e explicá-lo.

Para interpretar corretamente as sociedades dotadas de escrita, as ciências da arqueologia e da história convergem, constantemente, em relações multidisciplinares. Elas divergem, entretanto, quando os testemunhos escritos são raros ou pouco confiáveis, como na proto-história. Elas se separam quase integralmente nos estudos da pré-história, quando a arqueologia se encontra sozinha, por serem ágrafos os grupos humanos desse período.

Sem a arqueologia, seria impossível a reconstrução intelectual das sociedades da pré-história. Seria impossível igualmente ter acesso às informações daquelas sociedades cujos documentos escritos não conseguimos ainda decifrar, como a escrita hieroglífica, denominada de Linear A, da civilização cretense. Seria praticamente impossível também conhecer muito sobre sociedades cujos documentos escritos são raros e com poucas informações úteis, tais como os documentos micênicos em grego arcaico (Linear B).
Trata-se, portanto, de buscar, de compreender e de proteger os testemunhos documentais que sobreviveram e, assim, de garantir a sobrevivência do futuro de nosso passado enquanto humanidade.

As duas disciplinas se constituíram com empréstimos recíprocos desde Tucídides, que afirmou ser a arqueologia o conhecimento do passado arcaico de uma sociedade, enquanto a história, o conhecimento dos eventos mais recentes, uma história do tempo presente.

Quem de nós já não imaginou ser arqueólogo ao acompanhar as aventuras, quase sempre inverossímeis, de alguns heróis de filmes recentes, como, por exemplo, as ações dinâmicas de Indiana Jones ou de Lara Croft? Considerado, pelo público, o arqueólogo ideal, Indiana Jones é um sedutor, com uma loira ou uma morena na garupa de seu cavalo, e um cavaleiro do bem. Antes de tudo, prefere improvisar, e não o vemos seguir métodos arqueológicos tradicionais. Nunca recusa uma boa briga com seu chicote de couro trançado, mas, ao mesmo tempo, é um intelectual culto, capaz de fazer citações de obras raras. Veste uma velha jaqueta de couro e usa sempre um chapéu de feltro, ambos cor de terra, para disfarçar a poeira. Raramente tem tempo de tomar banho, de fazer a barba e de trocar de roupa entre uma aventura e outra. Raramente dá as aulas, pelas quais é pago pela universidade. Seus alunos correm atrás dele em busca das notas do curso, obrigando-o a fugir pela janela de seu gabinete de trabalho e a imediatamente envolver-se em uma nova aventura. Nunca o vemos produzindo um artigo ou um livro para publicar, nem mesmo analisando seus 
achados no laboratório de arqueologia. Ele é um aventureiro, um explorador e um arqueólogo de campo. De maneira muito pragmática, para ele, a arqueologia é apenas uma vez referida em todos os filmes. Ela é assim definida na aula que dá na universidade: “A arqueologia é a busca de fatos e não da verdade" (INDIANA JONES, 1989), apontando que as descobertas arqueológicas restam para sempre, mesmo que as interpretações sobre elas possam variar.

A maioria dos arqueólogos, entretanto, reluta em se deixar reconhecer por essa representação de Indiana Jones. Poderíamos perguntar se as arqueólogas se reconhecem na belíssima e aristocrática representação de Lara Croft. Ela se caracteriza por seu cabelo sempre e impecavelmente penteado, mesmo quando em luta contra malévolos bandidos. Suas roupas sob medida, coladas ao corpo, evidenciam o corte e o estilo de um grande costureiro. Sua aparência é sempre a melhor possível, sem indicar, na sua pele, as mordidas de mosquitos ou as queimaduras do sol, provocadas pela vida ao ar livre. Seu preparo físico invejável é o de um atleta olímpico. Nem bússola, nem pá, nem espátulas, nem sacos ou etiquetas: suas moderníssimas e inseparáveis pistolas na cintura parecem ser o único equipamento necessário para as suas aventuras arqueológicas. Em seu castelo, na Inglaterra, a sua equipe de arqueologia se resume a um mordomo e a um técnico em informática, ambos muito competentes. Nunca a vemos solicitar verbas para a atividade de campo nem produzindo um relatório de suas pesquisas. Ela é também uma aventureira e uma arqueóloga de campo. De maneira muito pragmática, em um mundo de homens quase sempre malfeitores, ela guarda uma distância fria e firme dos que são representantes do mal e não evita se aliar aos que estão do lado do bem.

Essas representações nos lembram de que cinema é divertimento. Os seus produtores consagram essa impressão, quando o velho $\mathrm{Sr}$. Jones se volta para seu filho Indiana e diz, categoricamente: "Isto não é arqueologia, é uma luta contra o mal" (INDIANA JONES, 1989).

Empolga-nos, nesses filmes, a fascinação da descoberta e o prazer de colecionar o objeto raro e único, aquele que ninguém pode possuir. Indiana Jones busca a Arca da Aliança e Lara Croft, a Caixa de Pandora, transformando os estudos da cultura material da arqueologia na busca de objetos ricos em significado simbólico, mas com poucas possibilidades de serem encontrados na vida real. Sabemos, há muito, que o estudo do passado não se resume à caça de tesouros excepcionais. Duvidamos também que a arqueologia seja apenas uma contínua guerra contra quadrilhas de malfeitores ou contra soldados inimigos. Nessas aventuras, entretanto, nunca existe um tempo para a aplicação dos métodos da ciência nem se podem ver referências às reflexões teóricas em busca de um sentido, na reconstituição do nosso passado. A aventura arqueológica não é uma última cruzada contra o mal. Entretanto, a realidade é que muitos estudantes se voltaram para a arqueologia devido a esses filmes, os preferidos também entre muitos arqueólogos. Somos obrigados a reconhecer que esses filmes fizeram muito pela difusão e pela valorização da arqueologia. 
Sem dúvida, a exploração do passado parece ser muito apaixonante para algumas pessoas. A arqueologia dá asas à imaginação ao se referir a cidades perdidas, tesouros descobertos, escavações em lugares exóticos. Nem todas as pessoas interessadas terminam por se transformar em arqueólogos ou em historiadores, mas muitos irão aumentar o número dos participantes do turismo arqueológico mundial e visitarão os sítios arqueológicos mais célebres, de Pompéia a Machu Picchu, de Cnossos a Stonehenge.

Sabemos atualmente muito bem que buscar tesouros fantásticos em oásis perdidos no deserto, fugir de múmias alucinadas e assassinas, procurar extraterrestres ultra desenvolvidos tecnologicamente ou reunir coleções de objetos raríssimos e extravagantes (como crâneos de cristal translúcido, por exemplo) não resume o que é a arqueologia. Essas visões, muito simplificadoras e um pouco preguiçosas do cinema e da televisão sobre a arqueologia, tantas vezes apresentadas e reapresentadas pela mídia, iludem-nos e levam-nos à redução de uma ciência à sua caricatura.

\section{0 que tem no passado?}

Por que nos preocuparmos com o passado da humanidade, se ele está fora de nosso alcance e nada poderemos fazer para modificá-lo? Não se trata de uma perda de tempo, uma vez que as pessoas a que diz respeito estão mortas?

Longe de ser uma aventura ou um divertimento de final de semana, a arqueologia se situa entre as ciências humanas, ao lado da história e da antropologia. Ela também se aproxima das ciências da natureza, quando utiliza os dados da geologia e da paleontologia, para as reconstituições das paleopaisagens, ou os métodos de datação da física, para organizar as suas cronologias, baseadas no Carbono 14.

O homem é uma extraordinária singularidade no mundo dos seres vivos ao se perguntar sobre as suas origens, ao construir discursos míticos ou históricos sobre seu passado e ao escavar o solo e encontrar os arquivos, que contêm os vestígios de seus antecessores. Somos responsáveis por esses milhares de vestígios da cultura material, que nos abrem novas perspectivas através de seu estudo, em busca das respostas que cada geração formula sobre o seu passado e o da humanidade.

Como nós a concebemos hoje, a arqueologia tem uma função social extremamente importante. Todas as sociedades se interrogam sobre as suas origens e buscam respostas. Na ausência de evidências científicas, elas criam mitos de origem e lendas sobre heróis e heroínas que explicam o passado longínquo. Muitas dessas sociedades terminam por encontrar os vestígios materiais, produzidos por gerações já desaparecidas, e reconhecem, nestes vestígios materiais, as evidências do passado que procuravam.

Nós conhecemos a arqueologia essencialmente através de alguns dos seus conceitos básicos, desconhecidos do homem comum: estruturas de combustão, tecnotipologia, decapagens em grandes superfícies, arqueometria, quadrículas, cadeias operatórias, etc. São palavras de um tipo muito especial, utilizadas para descrever e explicar o que fazemos nos sítios arqueológicos. São conceitos fundamentais para relatar os pro- 
cedimentos adotados no tratamento dos vestígios encontrados. Não são, pois, verdadeiramente os fenômenos que se produziram no passado. Essas palavras são organizadas em textos que tentam, com maior ou menor sucesso, ser uma representação discursiva do passado. Além disso, elas são muitas vezes polissêmicas e podem significar coisas diferentes para cada um de nós.

É o caso da própria palavra arqueologia que se refere tanto a realidades das sociedades do passado, como ao conhecimento que tentamos produzir hoje sobre esse passado. É formada por dois vocábulos gregos: archaios (antigo, relacionado às origens) e logos (discurso). Na Grécia, a arqueologia foi, antes de tudo, um discurso sobre as origens de uma sociedade, uma história da antiguidade. Ela nasceu entre os gregos, mais explicitamente na obra de Tucídides, na qual a Arqueologia é uma introdução histórica à Guerra do Peloponeso, entre Atenas e Esparta. Nessa introdução, explicam-se as origens das populações envolvidas e as razões históricas do conflito. Ignorado pelos romanos e esquecido na Idade Média, o termo se difundiu entre as línguas europeias apenas no Renascimento.

Para muitos gregos, os mitos eram as suas verdades, enquanto, para outros, as verdades eram as da sua história. Quando o homem se transformou em medida de todas as coisas, os mitos perderam seu lugar para a história. Na sociedade grega, entretanto, essa transformação foi lenta e progressiva: o mito e a musa Clio coexistiram à produção do conhecimento da história e da arqueologia. A própria crença na musa Clio parece evidenciar essa pluralidade de verdades ou de crenças.
Isso ocorreu exatamente no mesmo contexto histórico em que Heródoto e Tucídides ofereceram a Clio uma situação de destaque invulgar. Devido à qualidade de seus trabalhos, conferem à Clio uma posição de pioneira, uma data de nascimento na polis grega e um lugar de supremacia entre as demais ciências humanas, que começarão a surgir somente mais tarde. Eles lançaram as bases de uma nova metodologia e de uma abordagem original do passado. Para Heródoto, na ausência de arquivos documentais, valia a primazia do testemunho pessoal: o ver e o ouvir dizer. Não apenas o testemunho oral de um informante, mas também o testemunho (histor) do próprio historiador, como participante engajado, eram legítimos. Tucídides reproduz essa metodologia de maneira mais objetiva ainda, fazendo os mitos desaparecerem na sua história da Guerra do Peloponeso, ao descrever a Grécia como uma terra deserta de deuses, habitada por homens. Estes são apresentados como os únicos responsáveis pelos fatos descritos. $\mathrm{Na}$ ausência de arquivos documentais escritos sobre o passado remoto, Tucídides se refere à arqueologia quando escreve sobre as origens da sociedade grega, mostrando como é possível produzir informações sobre a história do passado com a análise dos elementos materiais da cultura. Ele é o pioneiro nesse tipo de abordagem e, graças a ele, Clio é a musa da história e também da arqueologia.

\section{Ciência da arqueologia}

Ao estudarmos as práticas e as reflexões que deram vida e coerência à pesquisa sobre o passado humano, nós nos voltamos 
também para o estudo epistemológico da ciência arqueológica. Em primeiro lugar, precisamos saber como ela chegou a ser o que é atualmente. Em segundo lugar, devemos compreender o que a arqueologia é nos dias de hoje.

A produção do conhecimento sobre o passado não é uma atividade natural, mas uma prática social apreendida em uma formação profissional específica, situada em um contexto histórico, transformando-se ao longo do tempo. Neste início de século XXI, a arqueologia pode se vangloriar de ter adquirido certa autonomia universitária. Os arqueólogos que se voltam para a pesquisa acadêmica organizaram a sua formação profissional nos bacharelados, nos mestrados e nos doutorados. Realizam inúmeras reuniões científicas, sobretudo congressos internacionais e nacionais, bem como seminários temáticos. Elaboraram os seus manuais técnicos e divulgam a sua produção intelectual em numerosas publicações: revistas e livros científicos. A comunidade dos arqueólogos conseguiu também o seu lugar entre as demais ciências humanas e naturais nas agências de fomento à pesquisa, como os conselhos nacionais e as fundações estaduais.

Sabemos que se posicionar criticamente sobre as práticas e as reflexões dos arqueólogos, dos historiadores e dos antropólogos não é atividade natural, mas aprendida em uma formação profissional, quase sempre em instituições superiores de ensino. Um arqueólogo formado na Europa (Alemanha, França ou Inglaterra) não terá necessariamente a mesma formação que outro formado na América (Estados Unidos ou Brasil), por serem contextos e, provavelmente, épo- cas diferentes. Mas todos deverão ter um objetivo em comum: fazer a melhor arqueologia possível.

Os estudantes em processo de formação universitária apresentam muitas dificuldades em se localizar nos embates travados pelos arqueólogos, seus futuros pares, ao longo do processo de construção da disciplina. Evitam, muitas vezes, tomar posição face aos debates epistemológicos, surgidos em cada uma das mudanças de orientação. Nem sempre se sentem capazes de uma postura mais reflexiva sem assumir posicionamentos ideológicos simplistas. Muitas vezes têm uma tendência a cair na total incompreensão, fugindo da leitura dos textos teóricos e abandonando-se aos dados empíricos das práticas, obtidos em campo ou nos arquivos documentais, sua única certeza.

Deveríamos ser sempre capazes de ver, na produção sobre o passado e na atividade dos arqueólogos, o resultado de uma atividade profissional incessante. O seu mérito não é apenas conhecer e reconstituir o passado de sua própria ciência, mas também a produção intelectual do melhor conhecimento possível sobre as sociedades humanas de todos os tempos e de todos os lugares.

Muitas são as questões epistemológicas fundamentais que surgem ao longo de um estudo que se propõe a refletir sobre o nosso passado e sobre aqueles que o praticam, os arqueólogos. Ao contrário de muitas outras sociedades, a nossa apela para Clio, ou seja, para os arqueólogos e os historiadores, em busca de explicações sobre o processo histórico. Serão construções mentais de nossa sociedade ocidental, já que grande parte das sociedades conhecidas se contenta 
com as explicações míticas e lendárias? A arqueologia apenas escava sítios e estuda, em laboratório, as coleções de cultura material obtidas? Ou também se preocupa com os aspectos simbólicos da cultura? Os arqueólogos elaboram teorias de curto, de médio ou de longo alcance? Será a arqueologia a produção de uma descrição (sem muitas explicações), como os relatórios que a maioria das pesquisas atuais de arqueologia de contrato propõe? Quem é o arqueólogo ideal: Lara Croft ou Indiana Jones? Quantas arqueologias existem? A arqueologia seria a soma de todas as arqueologias possíveis? Teriam essas perguntas múltiplas respostas? Existe ainda outra pergunta, de maior importância e anterior as já referidas: o que pretendemos ao estudar as práticas e as reflexões da arqueologia?

\section{Epistemologia}

Ao buscarmos respostas a essas e a outras possíveis questões, visamos uma discussão sobre o que se convencionou denominar de epistemologia da ciência. $\mathrm{O}$ termo epistemologia tem sua origem do grego: epistême (ciência, conhecimento) e logos (discurso, estudo). Esse conceito é polissêmico, ou seja, pode ter sentidos um pouco diferentes. Pode ser interpretado como teoria do conhecimento de um modo geral, englobando o estudo de todos os modos de conhecimento. Outro sentido, mais restrito, refere-se à filosofia das ciências. Trata-se do estudo de um tipo específico de conhecimento, que é o científico. Esse conhecimento deve ser estudado de maneira ampla, pois o conhecimento científico é muito diversificado e, como consequência, plural. Como temos sempre que nos referir à pluralidade das ciências (exatas, da terra, biológicas, humanas, etc.), trata-se de estudar, em cada caso, uma ciência em particular. Devemos saber compreender a história de cada uma delas, seus princípios fundamentais, seus territórios específicos, seus objetivos, suas escolas, seus paradigmas, seus fundamentos lógicos, seus debates internos, suas mudanças de rumo e o perfil dos seus especialistas. Trata-se de compreender cada uma das ciências em cada época de sua constituição, pois todas as ciências se encontram em construção, algumas delas, desde suas origens no mundo antigo, outras, desde os séculos XIX e XX. A epistemologia das ciências é um estudo recente. Atualmente todas as ciências são estudadas do ponto de vista epistemológico: a física, a química, a matemática, a biologia, a economia, a sociologia, a história, a antropologia, etc. Estuda-se, sobretudo, a construção histórica de cada uma das ciências sob uma dupla perspectiva: por um lado, as representações mentais e as ideias dos cientistas nas suas tentativas de explicar o planeta, a natureza e as sociedades humanas; por outro lado, os contextos históricos e as instituições sociais que possibilitaram a emergência das ciências desde as origens até nossos dias.

O processo de estruturação e de desestruturação das ciências, das suas crises e de suas alterações de paradigmas, desenrola-se ao longo do tempo. Estudar cada uma das ciências significa reviver a sua trajetória, os obstáculos e as rupturas que terminaram por favorecer a emergência de novos paradigmas e mudanças de rumo, o que alguns 
denominam de revolução científica. Neste longo e agitado processo, ocorre a articulação e a rearticulação dos conceitos chaves de maneira coerente.

O especialista em epistemologia das ciências Karl Popper tentou definir as condições de um procedimento científico rigoroso. Para ele, é o critério de falseabilidade ou, melhor, de refutabilidade que assegura à ciência sua capacidade de submeter suas hipóteses à sua refutação. Popper é o responsável por desvelar outro aspecto das ciências: o de que as teorias científicas são sempre uma teia de hipóteses mais ou menos válidas, mas sempre passíveis de serem refutadas. Para ele, a ciência possui, no seu variado e complexo campo de atuação, verdades provisórias e postulados nunca demonstráveis, como, por exemplo, a concepção do que ocorre com duas paralelas no infinito, um fenômeno que ninguém jamais viu, em um lugar no qual ninguém jamais esteve. $\mathrm{Ou}-$ tro especialista em epistemologia é Thomas S. Kuhn. Ele afirmou que, em cada época, a ciência se apoia em paradigmas (concepções dominantes) que são derrubados quando ocorre uma mudança de gerações por revoluções científicas. Para o autor, a ciência não evolui de maneira contínua, mas aos saltos. Em cada época, constata-se efetivamente a existência de um modelo dominante ou de um paradigma.

Ao estudarmos uma ciência, ao longo do tempo, como a arqueologia, temos que levar em conta que, desde as origens até a atualidade, estamos diante de uma ciência em construção. Ou seja, estamos tratando de um objeto de estudo cujo inacabamento é essencial. É no seio de uma arqueologia em pleno devir que podemos buscar os debates dos arqueólogos sobre as suas práticas e as suas reflexões teóricas, ou seja, reconstituir as certezas, as hesitações e as dúvidas dos arqueólogos ao longo do tempo. A longa caminhada de uma ciência nos coloca face a face com os limites do seu inacabamento, enquanto simples crônica de realidades do passado e possibilidades de trajetória, até se tornar, no mundo contemporâneo, uma das ciências, especificamente, uma das ciências humanas ou sociais.

\section{A autocrítica}

Ao questionarmos a arqueologia que se produz recentemente, não pretendemos defender um novo modelo que poderá substituir os anteriores. Trata-se de acompanhar criticamente os debates e os embates da discussão científica da construção da ciência ao longo de uma perspectiva histórica.

A epistemologia da arqueologia consiste, portanto, em interrogá-la, a fim de propor novos dados, de aumentar sua capacidade de explicitação e de sugestão. Por exemplo, um dos problemas epistemológi$\cos$ da arqueologia coloca não só a questão da relação entre o arqueólogo e seu tema, mas também da relação entre o arqueólogo e seu tempo. Qualquer resposta a essas questões seria incompleta sem levar em conta o arqueólogo, a arqueologia e a sociedade.

Dois aspectos importantes devem ser destacados, para que se possa compreender esse tipo de discussão. Em primeiro lugar, a análise dos caminhos seguidos por uma ciência é tema comum na teoria do conhecimento. Se a teoria do conhecimento levou, 
durante muito tempo, os filósofos da ciência a realizar análises sobre os métodos e os tipos organizacionais dos conhecimentos, atualmente, são os arqueólogos que realizam a crítica de sua própria investigação. Essa é uma forma salutar de autocrítica que deve ser contínua e sistemática. Em segundo lugar, há um reconhecimento, geralmente aceito, da necessidade que temos de aprimorar os nossos instrumentos de pesquisa. Para a busca do conhecimento sobre o passado das populações que compõem a humanidade ao longo deste imenso processo histórico e nos múltiplos espaços e paleopaisagens deste planeta, nós necessitamos de inúmeros e, muitas vezes, sofisticados instrumentos (KERN, 1996, p. 7-22).

O discurso científico de uma arqueologia teoricamente orientada não será jamais a mesma linguagem dos homens do passado. Haverá uma substancial diferença entre os sistemas de análise empregados hoje e os sistemas de signos dos homens do passado. Assim, será impossível confundir a teoria atual com a realidade do passado. Devemos igualmente nos limitar a uma melhor explicitação das demonstrações e de nossas interpretações, sem almejar a transformação do nosso discurso teórico em uma formulação matemática, como o de muitas ciências da natureza, pois perderíamos de vista esse conjunto complexo e multiforme das sociedades humanas.

Ao tomarmos conhecimento das nossas limitações para a reconstituição do passado, devemos evitar cair no niilismo. Mesmo partindo de uma concepção socrática, de que sabemos muito bem que nada sabemos, e de que nossas reflexões nunca serão direta- mente confirmáveis, pois as populações do passado não podem mais ser estudadas diretamente, devemos ter consciência de que o pessimismo pode ser superado. Poderemos sempre criticar racionalmente nossas teorias e, continuamente, aprimorá-las, distinguindo-as de teorias piores.

Para muitos arqueólogos, a sua ciência continuará a se desenvolver no futuro, porque é a única disciplina capaz de estudar 99 por cento de toda a história da humanidade. Apenas a arqueologia pode nos informar sobre o surgimento de conquistas culturais de grande importância para as origens e para o desenvolvimento da humanidade: as origens da agricultura e da arte, da tecnologia e da urbanização, das sociedades complexas e da escrita: "Se nós quisermos saber para onde estamos indo, necessitamos reconstituir a nossa trajetória, para vermos de onde viemos. Eis porque a arqueologia é tão importante" (BAHN, 1996, p. 98).

Um historiador inglês afirmou recentemente que:

Muitos de nós consideram ser este o nosso trabalho, isto é, virar as costas para onde quer que estejamos indo e focalizar a nossa atenção, de qualquer ponto vantajoso em que nos acharmos, para onde estivemos. Percebemos formas através da névoa e da bruma, podemos especular sobre seu significado e, algumas vezes, podemos concordar sobre o que elas são (GADDIS, 2003, p. 15-17).

As atuais gerações têm a responsabilidade de evitar a destruição dos arquivos do solo e a obrigação de estudar esses vestígios arqueológicos, garantindo, assim, o futuro do nosso passado. 
As ciências se definem pelas regras de seus discursos específicos, como os especialistas em epistemologia sabem nitidamente. Elas não são estáticas e, muito menos, um conjunto de conhecimento fixo e imutável:

Talvez nunca seja demasiado recordar que - ao contrário das doutrinas - a ciência não é um corpo de conclusões fixas e indubitáveis, mas sim um somatório de resultados não definitivos de um contínuo processo de investigação, no qual está sempre presente um método intelectual de crítica (KERN, 1982, p. 65).

As ciências são construídas, pouco a pouco, pelas diversas gerações de pesquisadores. Por isso mesmo todas têm uma história, e cada mudança de sentido ou de orientação está relacionada aos seus próprios progressos metodológicos e à discussão teórica entre seus pares, bem como aos contextos históricos de cada época: "Supor e afirmar que há uma 'verdade' absoluta, intangível e eterna, não pertence à ordem do discurso científico" (DEMOULE, 2005, p. 187). Ciência em construção e reconstrução constante, a arqueologia não foge a essa tendência geral de todas as ciências.

Mortimer Wheeler, um dos maiores arqueólogos ingleses de nossa época, lembrou, certa vez, que as definições não esclarecem necessariamente, mas que a investigação científica se desenvolve em função da dúvida sistemática, pois apenas a ignorância julga possuir todas as respostas ${ }^{1}$. Torna-se necessário recordar que o pesquisador desconfia também de quem tem sempre as mesmas respostas para todas as questões, inclusive para as que ainda nem foram pensadas. Entretanto, podemos refletir sobre algumas características que delimitam os territórios onde atuam os arqueólogos. Paul Courbin afirma que o problema não é apenas tentar definir a arqueologia pelo seu conteúdo, mas também identificar aquilo que a distingue das demais ciências naquilo que só os arqueólogos são capazes de fazer (COURBIN, 1982).

\section{Aarqueologia}

Uma ciência se distingue das demais pela maneira de visar seus objetos. Não se trata de um método único, pois cada ciência tem diversos métodos para atingir seus objetivos. A arqueologia é uma comprovação disso pela multiplicidade de métodos que emprega. Existem diversos métodos científicos criados e utilizados pelos arqueólogos. Outros são apropriados pelas relações interdisciplinares com as ciências da natureza e as ciências sociais. Entretanto, existe somente uma visão propriamente científica característica da arqueologia. Essa ciência nos apresenta uma visão própria da realidade a partir de seu estudo do passado através da análise da cultura material (GRANGER, 1994, p. 45-48).

A arqueologia não é um estudo direto de uma sociedade no passado, como já se afirmou, mas um estudo indireto sobre os grupos humanos do passado a partir dos vestígios que sobreviveram ao tempo, estes sim analisados diretamente. Ela busca descrever e explicar as evidências materiais encontradas nos sítios arqueológicos, para podermos compreender melhor nossas origens e nossa herança cultural. No caso dos sítios pré-históricos, a inexistência de documentos escritos faz com que esse objetivo seja alcan- 
çado tão somente pelos vestígios da cultura material. Quando se trata de sítios históricos, entretanto, sempre que possível, o arqueólogo confronta as evidências da cultura material com as fontes primárias escritas.

A história e a arqueologia são, muitas vezes, vistas de uma maneira muito romântica, como uma paixão pelo passado ou como uma viagem no tempo. Como toda a viagem no tempo, essas duas ciências têm seus trajetos, seus perigos, suas escalas e seus portos. Entretanto, quanto mais essa paixão parecer romântica, mais ela correrá o risco de perder sua substância. Ao se voltar para si mesma, em um processo de dessecação, a ciência pode parecer, tão somente, um passatempo fútil (SCHNAPP, 2005). Nós sabemos que as ciências têm uma função social importante. A arqueologia e a história somente serão reconhecidas socialmente se produzirem um conhecimento válido para a sociedade.

As pesquisas arqueológicas sobre o nosso passado não podem ser vistas de maneira inconsequente ou como um conhecimento inútil. Os mitos de criação, elaborados cuidadosamente por quase todas as sociedades conhecidas, evidenciam-nos como a humanidade tem demonstrado uma necessidade fundamental de se voltar para suas origens e de deixar explícita a sua identidade étnica, baseada em uma herança cultural específica.

O saber arqueológico, construído cientificamente, somente é válido se atender aos critérios de validação da ciência, que são: tornar explícitos os caminhos pelos quais foi obtido e as condições nas quais pode ser reproduzido. Esse conhecimento é necessariamente público e produzido de maneira competente (GRANGER, 1994). Ele será sempre passível de uma discussão epistemológica entre os pesquisadores de seu campo do saber. Como todas as ciências, continuamente em construção, nem sempre a arqueologia pode fazer afirmações taxativas e definitivas como gostaríamos. Entretanto, suas afirmações e conclusões são sempre obtidas por um número muito grande de evidências, que permite a validação de suas interpretações. Por um lado, artefatos arqueológicos paleolíticos podem nos evidenciar as origens remotas da humanidade ao serem datados com mais de dois milhões de anos de idade. Artefatos similares podem nos provar o início do povoamento das paisagens da América Meridional Platina, com datações de onze mil anos atrás, no final da última glaciação. Por outro lado, arqueólogos podem estar escavando estabelecimentos industriais na Inglaterra do século XIX e os solos dos centros históricos de nossas cidades, em pleno século XXI. Esses extremos cronológicos podem nos fazer compreender melhor uma história de longa duração que a arqueologia nos evidencia a partir da cultura material.

Trata-se de reconstituir, a partir dos estudos sobre a cultura material remanescente do passado,

[...] as venturas e as desventuras pelas quais passou a espécie humana, as transformações orgânicas evolutivas ocorridas, os progressos técnico-econômicos desenvolvidos, as diversas formas de organização sociopolíticas criadas, as manifestações artísticas e religiosas imaginadas, e as longas migrações realizadas cheias de riscos $\mathrm{e}$ aventuras (KERN, 1994, p. 7).

Tempo curto ou tempo longo, olhar vertical da diacronia ou olhar horizontal da sincronia, a arqueologia projeta múltiplas 
visões possíveis sobre o passado. Nas últimas décadas, a ampliação do debate sobre a importância desse tipo de arqueologia e de suas importantes relações com a ciência histórica foi claramente referido pelos historiadores franceses (SCHNAPP, 1976, 1990; PESEZ, 1990). Trata-se de um reconhecimento não só da multiplicidade do olhar do arqueólogo sobre a complexidade da aventura humana, como também da nova consciência que temos da obrigação de seguir todas as pistas para a reconstituição do passado.

A arqueologia não é uma disciplina nova, mas segue sempre em um desenvolvimento constante, buscando suas marcas, as fronteiras de seu território de pesquisa, compreendendo ser necessário abrir seus horizontes, o mais possível. Uma das características mais marcantes da atual pesquisa arqueológica é a ampliação de seus territórios, de seus campos de atuação. Esse fato pode ser especialmente observado nos campos da arqueologia realizados entre nós.

A arqueologia é, sem dúvida, uma ciência que atualmente se encontra em plena construção, com as inevitáveis dificuldades de ordem teórica e metodológica das ciências sociais, em especial da antropologia e da história. Paul Courbin nos recordou, certa vez, que: "os europeus se interessam antes de tudo à História, e os americanos, sobretudo, à Antropologia" (COURBIN, 1982, p. 208). Historiadores e antropólogos afirmaram, até os anos 1960, que a arqueologia era uma mera técnica auxiliar de suas disciplinas. Entretanto, é exatamente a partir dessa década que ela, pouco a pouco, se define como uma ciência ainda nova e, portanto, em construção. Publicada em 1948, não é nada recente a afirmação de Walter Taylor de que "a Arqueologia não é nem História, nem Antropologia" (TAYLOR, 1948. p. 44). Mas, por ser ainda em grande parte desconhecida, a afirmação é desafiadora ao afirmar que sem ser nem História, nem Antropologia, a arqueologia seria mais uma das ciências humanas. Para alguns historiadores e antropólogos, ela seria uma ciência auxiliar, enquanto, para outros pesquisadores, entre eles os arqueólogos, ela seria uma ciência autônoma. Talvez seja a diversidade dos campos de pesquisa que termina por obscurecer a definição de arqueologia, pois os arqueólogos escavam desde cavernas pré-históricas e barcos naufragados a centros históricos das cidades atuais. Para Jean-Marie Pesez, talvez se pudesse concordar que a arqueologia tem como objetivo o conhecimento do passado dos homens a partir dos vestígios materiais que produziram, consumiram e abandonaram.

Essa afirmação não explicaria, entretanto, as relações com as outras ciências que estudam o passado do homem nem a situação de ciência independente. Segundo este arqueólogo, o conceito de arqueologia implica a noção de ciência independente por ter seu domínio particular e seus métodos próprios. É claro que nenhuma definição é plenamente satisfatória, pois precisa satisfazer tanto ao arqueólogo que encontra bibliotecas de tabuinhas cuneiformes nos tells do Oriente Próximo, como ao que recolhe milhares de inscrições paleográficas em casca de árvores no sítio de Novgorod. A arqueologia, para Pesez (1997), não se define apenas pelos seus domínios, pelos seus campos de atividades. Esses territórios, que os 
arqueólogos exploram, variam muito com o período do passado em estudo. Se nós nos referimos aos sítios da pré-história, a arqueologia apenas tem como limites aqueles que lhe impõe o tipo de documento, pois somente resta do passado a cultura material.

Os arqueólogos raramente poderão se interessar pelos fatos de curta duração, quase sempre pouco acessíveis. Eles deverão dirigir os seus olhares para os fatos de média e de longa duração, ou seja, para aqueles relacionados ao desenvolvimento dos homens desde a emergência da humanidade na pré-história até a existência das civilizações. Na arqueologia pré-histórica, deverão se consagrar às origens dos primeiros seres humanos (homo habilis, homo erectus, homo sapiens de Neandertal, homo sapiens sapiens), às atividades quotidianas de seu modo de vida, aos contextos ambientais (glaciações e inter-glaciares, transgressões e regressões marinhas) aos quais se adaptam através da cultura que produzem, às culturas definidas pela sua tecnologia, seus aspectos culturais e artísticos. A arqueologia histórica, que volta os seus interesses para os sítios das sociedades que conhecem a escrita, conheceu também, inicialmente, limites muito estreitos. A arqueologia medieval, por exemplo, dedicou-se durante muito tempo ao estudo arquitetural dos edifícios religiosos (igrejas românicas e góticas) e dos castelos feudais. Hoje isso não ocorre mais, pois a arqueologia histórica não se fecha a nenhuma direção de pesquisa, estando voltada também para as atividades do quotidiano de todos os componentes sociais da população estudada, bem como para a organização das sociedades no tempo. É perfeitamente compreen- sível que ela tenha que levar em conta não só os documentos materiais, mas também o auxílio inestimável da ciência histórica, que se fundamenta, sobretudo, nos documentos escritos.

Mesmo que a arqueologia, como qualquer ciência, não possa sempre fazer afirmações definitivas, somos obrigados a reconhecer que ela reúne um número impressionante de evidências. Esses conjuntos de dados nos permitem a elaboração de interpretações perfeitamente aceitáveis sobre o nosso passado.

Podemos afirmar que, como outras ciências, a arqueologia tende a ser uma ciência global no sentido das relações multidisciplinares que mantém tanto com as ciências humanas (antropologia, história), como com as ciências da natureza (física, biologia, geologia) e com a própria ciência exata da matemática, através da arqueometria. Isto se deve ao fato de que ela se interessa por tudo que diz respeito ao ser humano e à vida das sociedades humanas, do passado mais antigo ao passado mais recente, em todas as paisagens do planeta.

Trata-se de uma mera questão de definição? Pensamos ser muito mais do que isso. A arqueologia é atualmente conceituada de maneira ampla, como sendo a produção do conhecimento sobre o passado humano a partir da pesquisa dos vestígios materiais da cultura de todas as sociedades e de todas as épocas. E é ela que pode garantir um futuro ao nosso passado, ou seja, à humanidade dos homens no tempo. 


\section{Abstract}

Man is an extraordinary singularity in the world of living beings when he asks about his origins, when constructing mythical or historical discourses about his past, when digging the files of the ground and finding the vestiges of his predecessors. We are responsible for these thousands of vestiges of material culture, which open new perspectives to us in the moment in which they are studied, in search of the answers that each generation formulates on its past and the one of the humanity. The article evokes reflections on the epistemology and social function of archeology, highlighting the relevance of the study, comprehension and protection of documentary testimonies, thus guaranteeing the survival of the future of our past as humanity.

Keywords: Archeology. History. Science. Social role.

\section{Resumen}

El hombre es un singularidad extraordinaria en el mundo de los seres vivos a preguntarse acerca de sus orígenes, a construir discursos míticos o históricos sobre su pasado, al excavar los archivos de suelo y encontrar las huellas de sus predecesores. Somos responsables de estos miles de huellas de la cultura material, se nos abren nuevas perspectivas cuando estudiado en busca de respuestas que cada generación fórmula de su pasado y de la humanidad. El artículo evoca reflexiones sobre la epistemología y la función social de la arqueología, destacando la relevancia del estudio, la comprensión y la protección de las pruebas documentales, para asegurar así la supervivencia del futuro de nuestro pasado, mientras humanidad.

Palabras clave: Arqueología. Historia. Ciencia. Función Social.

\section{Nota}

1 Wheeler foi um dos maiores arqueólogos ingleses de nossa época e um renomado especialista no campo da Arqueologia Histórica romana, medieval e da Índia. Sua afirmação textual é: “No matter that in a majority of instances we cannot truly know: it is the privilege of the intelligent to ask questions, and the claim of the unintelligent to have all the answers. The state of philosofic doubt is not the least enviable of humans conditions. Definition does not necessary clarify" (DEMOULE, 2005, p. 229).

\section{Referências}

BAHN, Paul. The future of the past. In: Archaeology: a very short introduction. Oxford: Oxford University Press, 1996.

COURBIN, Paul. Qu'est-ce que l'archéologie? Paris: Payot, 1982.

DEMOULE, Jean-Paul. Théories et interpretations en archéologie. In : DEMOULE, JeanPaul; GILIGNY, François; LEHOËRFF, Anne; SCHNAPP, Alain. Guide des méthodes de l'archéologie. Paris: La Découverte, 2005.

GADDIS, John L. Paisagens da História. Rio de Janeiro: Campus, 2003.

GRANGER, Gilles-Gaston. A ciência e as ciências. São Paulo: UNESP, 1994. 
INDIANA JONES e a última cruzada. Diretor: Steve Spielberg. Produção: Robert Watts. Los Angeles: Paramount Pictures, 1989. 1 DVD. $127 \mathrm{~min}$.

KERN, Arno Alvarez. O papel das teorias como instrumental heurístico para a reconstituição do passado. Histórica (APGH-PUCRS), Porto Alegre, v. 1, p. 7-22, 1996.

Antecedentes indígenas. Porto Alegre: Ufrgs, 1994.

. As tendências atuais da ciência histórica. Ciências e Letras, Porto Alegre, v. 2, p. 12-18, 1982.

PESEZ, Jean-Marie. Histoire de la culture matérielle. In: LE GOFF, Jacques; CHARTIER, Roger; REVEL, Jacques. La Nouvelle Histoire. Paris: Retz/C.E.P.L., 1978. p. 202-222.

. História da Cultura Material. In: LE GOFF, Jacques; CHARTIER, Roger; REVEL, Jacques. A História Nova. Coimbra: Almedina, 1990. p. 48-62. (Edição em língua portuguesa)

L'Archéologie: mutations, missions, méthodes. Paris: Nathan, 1997.

SCHNAPP, Alain. "A Arqueologia". In: LE GOFF, Jacques e NORA, Pierre. História: Novas Abordagens. Paris: Gallimard, 1974. Traduzido para o português pela Liv. Francisco Alves (Rio de Janeiro), em 1976.

Archéologie. In: LE GOFF, Jacques; CHARTIER, Roger; REVEL, Jacques. La Nouvelle Histoire. Paris, Retz/C.E.P.L., 1978. p. 88-90.

Arqueologia. In: LE GOFF, Jacques; CHARTIER, Roger; REVEL, Jacques. A História Nova. Coimbra: Almedina, 1990. p. 92-110.

Histoire de l'archéologie et l'archéologie dans l'histoire. In : DEMOULE, Jean-Paul; GILIGNY, François; LEHOËRFF, Anne; SCHNAPP, Alain. Guide des méthodes de l'archéologie. Paris: La Découverte, 2005.

TAYLOR, Walter W. A study of archaeology. Carbondale: Southern Illinois Press, 1948. 